\title{
Halacarid Mites of the Genus Actacarus (Acari: Halacaridae) from Hokkaido, Northern Japan
}

\author{
Hiroshi Abé• \\ Department of Marine Sciences and Technology. \\ Hokkaido Tokai University. Sapporo, 005 Japan
}

(Received 26 December 1996; Accepted 24 February 1997)

\begin{abstract}
Three species of the marine mite genus Actacarus occurring on the coast of Hokkaido, northern Japan, are described. Actacarus pacificus Bartsch was found in the subtidal zone of Teuri Island; this species is recorded from the northwestern Pacific for the first time. Actacarus illustrans Newell was taken from the intertidal zone in Oshoro Bay, the Sea of Japan. A new species, $A$. octosetus, is described on the basis of specimens from intertidal sandy sediment in Uchiura Bay, southern Hokkaido. The new species is easily distinguished from its congeners in having 4 pairs of perigenital setae in the female and 34-40 perigenital setae in the male. Marine suctorians are associated with $A$. octosetus. A key to the Actacarus species in Hokkaido is given.

Key Words: New species, new record, marine mites, Actacarus, Halacaridac, Acari, suctorians, Hokkaido, Japan.
\end{abstract}

\section{Introduction}

The arenicolous halacarid mite genus Actacarus Schulz is commonly found in coarse sandy deposits in the intertidal and subtidal zones. Up to the present, 16 species have been described in the world, and 10 species have been recorded from the Pacific Ocean (Newell 1951, 1984; Krantz 1976; Bartsch 1977b, 1979, 1988, 1991a, 1993; Bartsch and Schmidt 1978; Abé 1990). Most previous surveys in the Pacific, however, have been carried out in the southern or tropical regions and the faunal knowledge from the northern area is still limited (Newell 1951; Krantz 1976; Abé 1990). Recently a meiofaunal survey was carried out around the coast of Hokkaido, northern Japan. During this survey, several halacarid mites were recovered from intertidal and subtidal sandy sediment. The present paper deals with 3 species of the genus Actacarus collected from the western and southern districts of Hokkaido.

Measurements are given in micrometers $(\mu \mathrm{m})$.

Abbreviations: $\mathrm{AD}$, anterodorsal plate; $\mathrm{PD}$, posterodorsal plate; $\mathrm{AE}$, anterior epimeral plate(s); PE, posterior epimeral plate(s); GA, genitoanal plate; ds, dorsal setae; dp, dorsal pores; aes-i, anterior epimeral setae; aes-ii-lat (-v), lateral (ventral) setae of coxae II ; pes-iii-lat (-v), lateral (ventral) setae of coxae III; pes-iv-a (-p), anterior (posterior) setae of coxae IV; p-1 to p-4, first to fourth segment of palp; L/W, ratio of length to width. 
Genus Actacarus Schulz, 1936

Actacarus Schulz, 1936: 327-331; André 1946: 35; Bartsch 1983: 188; Newell 1984: 242; Bartsch 1993: 74-75; Bartsch 1996: 231.

[Type species: Actacarus pygmaeus Schulz, 1936]

Diagnosis. AD and PD well developed. OC minute or lacking. PE with 3 or 4 setae. Female with 3 or 4 pairs of perigenital setae, lacking subgenital setae. Rostrum triangular with 4 pairs of rostral setae. Palp 4-segmented, laterad of rostrum. Legs slender; genu shorter than telofemur or tibia. Tarsus I with well developed fossary lamella bearing solenidion and famulus. Tarsus II with long dorsal solenidion. Carpite absent. Median claw present on all tarsi.

\section{Key to the species of Actacarus in Hokkaido}

1. AE with 4 pairs of epimeral setae. PE with 2 ventral setae.

A. pacificus.

-. AE with 3 pairs of epimeral setae. PE with 3 ventral setae.

2. Tarsus III with 4 dorsal setae. Female with 3 pairs of perigenital setae.

A. illustrans.

-. Tarsus III with 3 dorsal setae. Female with 4 pairs of perigenital setae.

A. octosetus sp. nov.

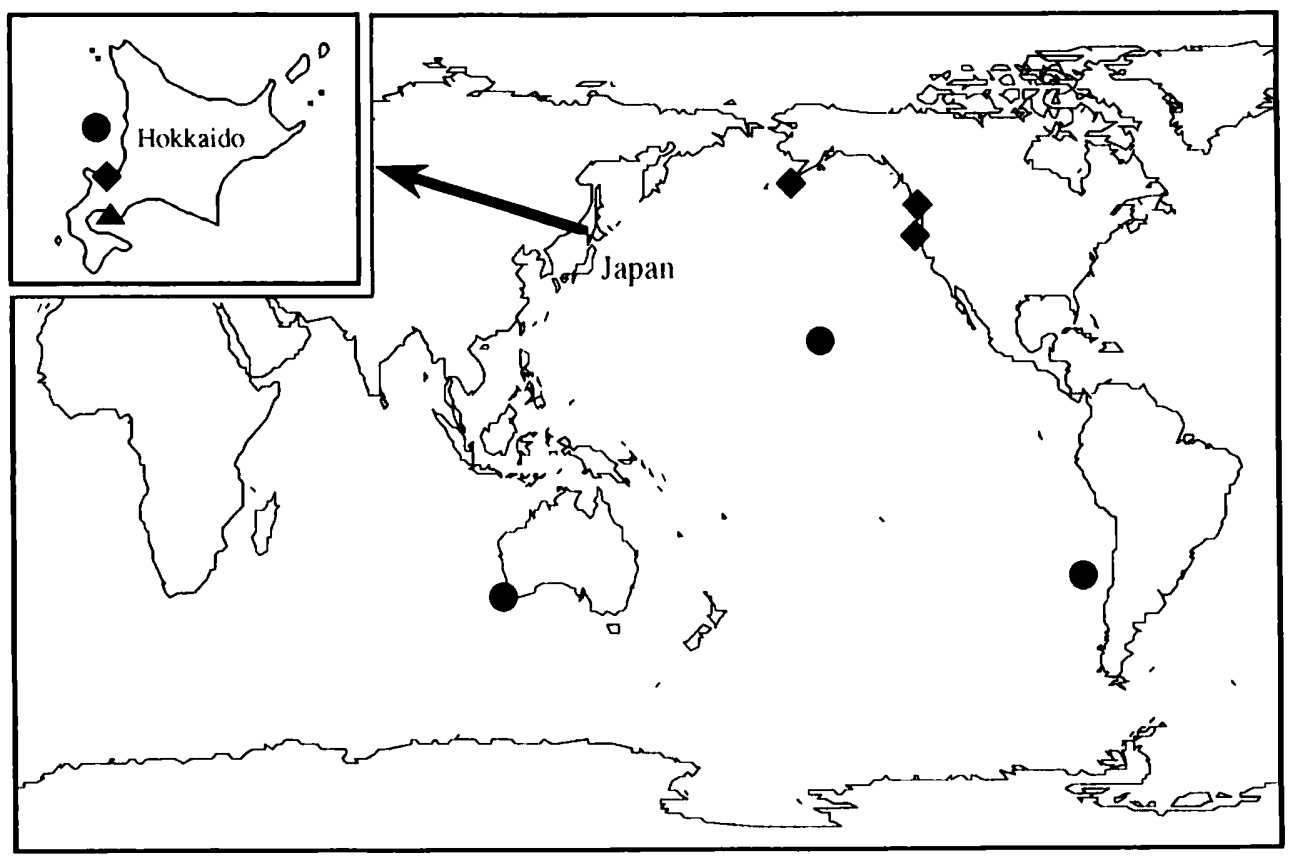

Fig. 1. Distribution of Actacarus pacificus ( ), Actacarus illustrans $(\diamond)$, and Actacarus octosetus sp. nov. ( $\mathbf{\Delta})$. 
Actacarus pacificus Bartsch, 1979

(Fig. 2)

Actacarus pacificus Bartsch, 1979: 231-234, figs 1-14; Bartsch 1988: 214; Bartsch 1993: 75-76, fig. 1; Bartsch 1996: 237.

Actacarus orthotectus Newell, 1984: 245-247, figs 705-707.

Specimens examined. Five 우우 and $3 \sigma^{\nearrow} \sigma^{\top}$, in coarse sand at $10 \mathrm{~m}$ depth in Sea of Japan off Teuri Island, Hokkaido, 18. ii.1989, H. Abé leg.
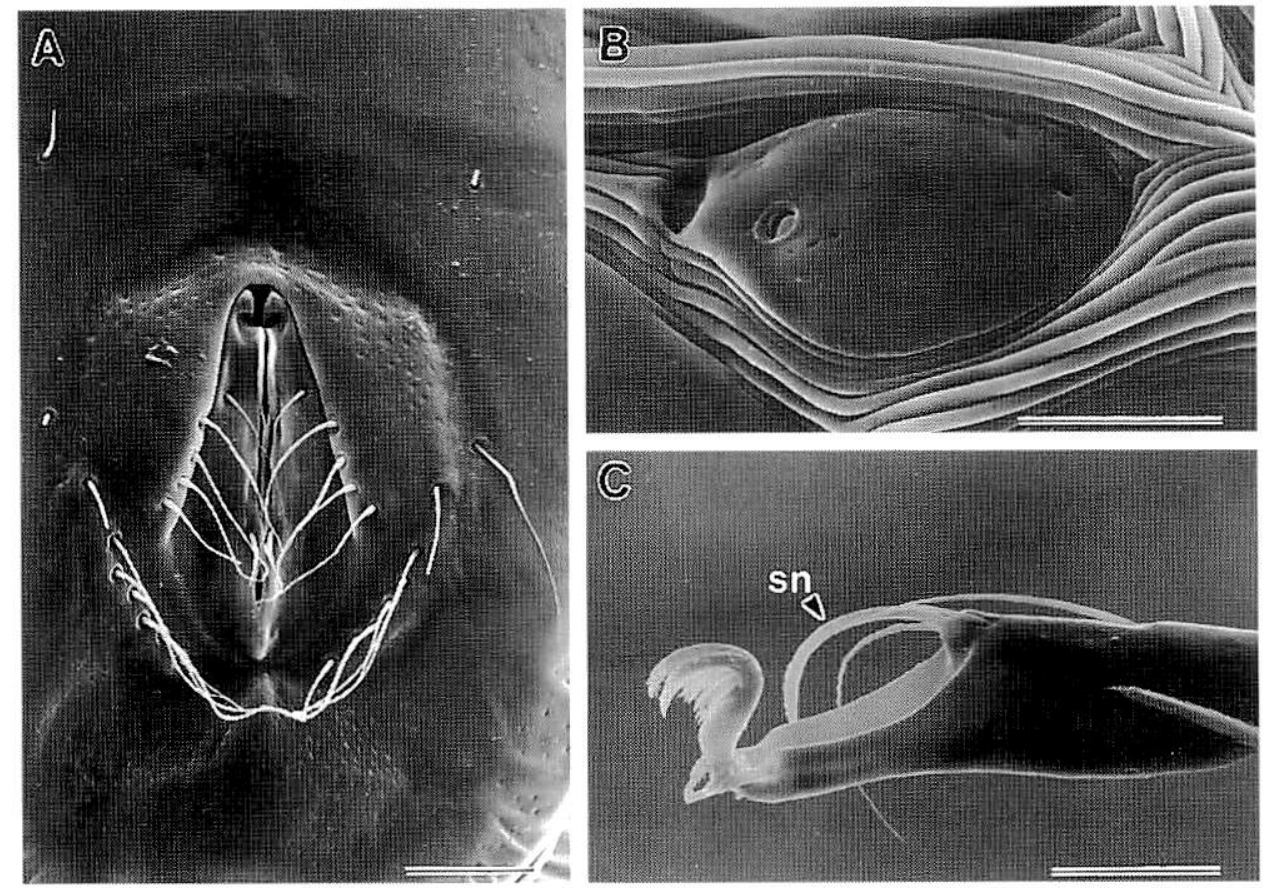

Fig. 2. Actacarus pacificus. Male: A, genital region; B, left ocular plate; C, distal region of left tarsus II. (sn, solenidion) Scale bars $=10 \mu \mathrm{m}$.

Description (specimens from Hokkaido). Idiosoma: female 285-355 long, 150-195 wide; male 265-365 long, 140-190 wide. Gnathosoma: female 85-98 long, 65-83 wide; male 85-98 long, 68-85 wide. AD 63-80 long, 88-135 wide. PD 170-263 long, 95-165 wide. OC (Fig. 2B) 23-35 long. Setae ds-i on AD, ds-ii on membranous cuticle, ds-iii- ds-vi (adanal setae) on PD. Pores dp- i on AD, dp-ii on OC, dp-iii and dp-iv on PD. AE 120-168 long, with 4 pairs of epimeral setae. PE 138-175 long, with 1 dorsal and 2 ventral setae. GA 105-145 long, 80-108 wide in female, 110-145 long, 80-110 wide in male. Perigenital setae in 3 pairs in female, 26-28 setae in male (Fig. 2A). Subgenital setae arranged 1-2 in male (Fig. 2A). Ovipositor long and tube-like, extending to halfway between insertions of legs III and IV. Length of legs I, II, III, IV $=175-260, \quad 153-215, \quad 168-253, \quad 175-260$, respectively. Leg chaetotaxy from trochanter to tibia as follows: Leg I, 0-(1, 2)-(2, 3)-(4, 5)-(6, 7); Leg П, 0-(1, 2)-(2, 
3)-(3, 4)-5; Leg III, 1-2-(2, 3)-3-(4,5); Leg IV, 1-(1, 2)-(2, 3)-3-(4,5). Tarsus I with 1 basidorsal seta, 2 filiform basal fossary setae, 1 anteroventral seta, 2 distiventral setae, and 2 parambulacral setae. Solenidion bacilliform, located on posterior surface of lamella. Famulus blade-shaped, placed on surface of lamella. Tarsus II (Fig. 2C) with 1 basidorsal seta, 2 basal fossary setae, and 2 parambulacral setae. Solenidion long and terminally expanded (Fig. 2C). Tarsus III with 3 fossary setae and anterior filiform and posterior bacilliform parambulacral setae. Tarsus IV with 3 fossary setae and anterior bacilliform and posterior filiform parambulacral setae.

Remarks. Bartsch (1996) synonymized $A$. orthotectus Newell, 1984 with $A$. pacificus Bartsch, 1979. Re-examination of the type series of $A$. orthotectus [holotype ( + ) and paratypes ( 2 \& $9,1 \delta, 1$ protonymph), sand, intertidal, Cumberland Bay, Tierra Island, Juan Fernandez Islands, Chile, 17 July 1966, R. Woollacott leg., Acari collection 5571Q-04, deposited in the National Museum of Natural History (USNM) collection at the Systematic Entomology Laboratory, USDA, Beltsville, Maryland, USA] supports her suggestion. This species has hitherto been recorded from the Hawaiian Islands (Bartsch 1979, 1988), southwestern Australia (Bartsch 1993), and Juan Fernandez Islands (Newell 1984). This is the first record of the species from the northwestern Pacific. The size range of the idiosoma shows some regional variation as follows: Hawaiian specimens (우 + , 194-240; $\delta \delta, 217-236$ ), Juan Fernande $z$ specimens (우우, 253-284; $\sigma^{\top}, 256$ ), Australian specimens (우우, 235-282; 지, 239-274), Japanese specimens ( $+9,285-355 ; \sigma^{\top} \sigma, 265-365$ ). The body size of the North Pacific specimens is noticeably larger than that of the other regional forms.

Distribution (Fig. 1). Indo-Pacific: Hawaiian Islands, Juan Fernandez Islands, southwestern Australia, Japan.

Actacarus illustrans Newell, 1951

(Fig. 3)

Actacarus illustrans Newell, 1951: 33-34, figs 126-140; Krantz 1976: 255-257, figs 30-32; Abé 1990: 112-118, figs 2-6; Bartsch 1996: 236.

Specimens examined. Five +9 and $3 \sigma^{7} \sigma$, in coarse sand at $0.1 \mathrm{~m}$ depth, Oshoro Bay, coast of Sea of Japan, Hokkaido, 9.v.1992, H. Abé leg.; 5 웅, $5 \sigma^{\nearrow} \sigma^{\prime}, 2$ protonymphs, and 1 deutonymph, in coarse sand at tidal line, Crofton, Vancouver Island, Canada, 17.vī.1995, K. Kinoshita leg.

Description (specimens from Hokkaido). Idiosoma: female 240-260 long, 105-125 wide; male 250-285 long, 110-140 wide. Gnathosoma: female 58-68 long, 48-55 wide; male 60-68 long, 50-53 wide. AD 50-68 long, 75-98 wide. PD 160-195 long, 83-115 wide. OC (Fig. 3B) 15-20 long. Setae ds-i on AD, ds-ii on membranous cuticle, ds-iiids-vi (adanal setae) on PD. Pores dp-i on AD, dp-ii on OC, dp-iii and dp-iv on PD. AE 98-113 long, with 3 pairs of epimeral setae. PE 115-150 long, with 1 dorsal and 3 ventral setae. GA 95-113 long, 75-80 wide in female; $95-125$ long, $70-85$ wide in male. Perigenital sctae in 3 pairs in female, 22-28 setae in male (Fig. 3A). Subgenital setae arranged $1-1$ in male (Fig. 3A). Ovipositor funnel-shaped, extending to midlength of GA. Length of legs I, II, III, IV =155-188, 138-160, 148-185, 153-185, respectively. Leg chaetotaxy from trochanter to tibia as follows: I.eg I, $0-(1,2)-(2,3)-(3,4,5)-(5,6)$; Leg II, 0-(1, 2)-(1, 2, 3)- $(3,4)-(4,5)$; Leg III, $(0,1)-(1,2)-2-3-(4,5)$; Leg IV, $(0,1)-(0$, 

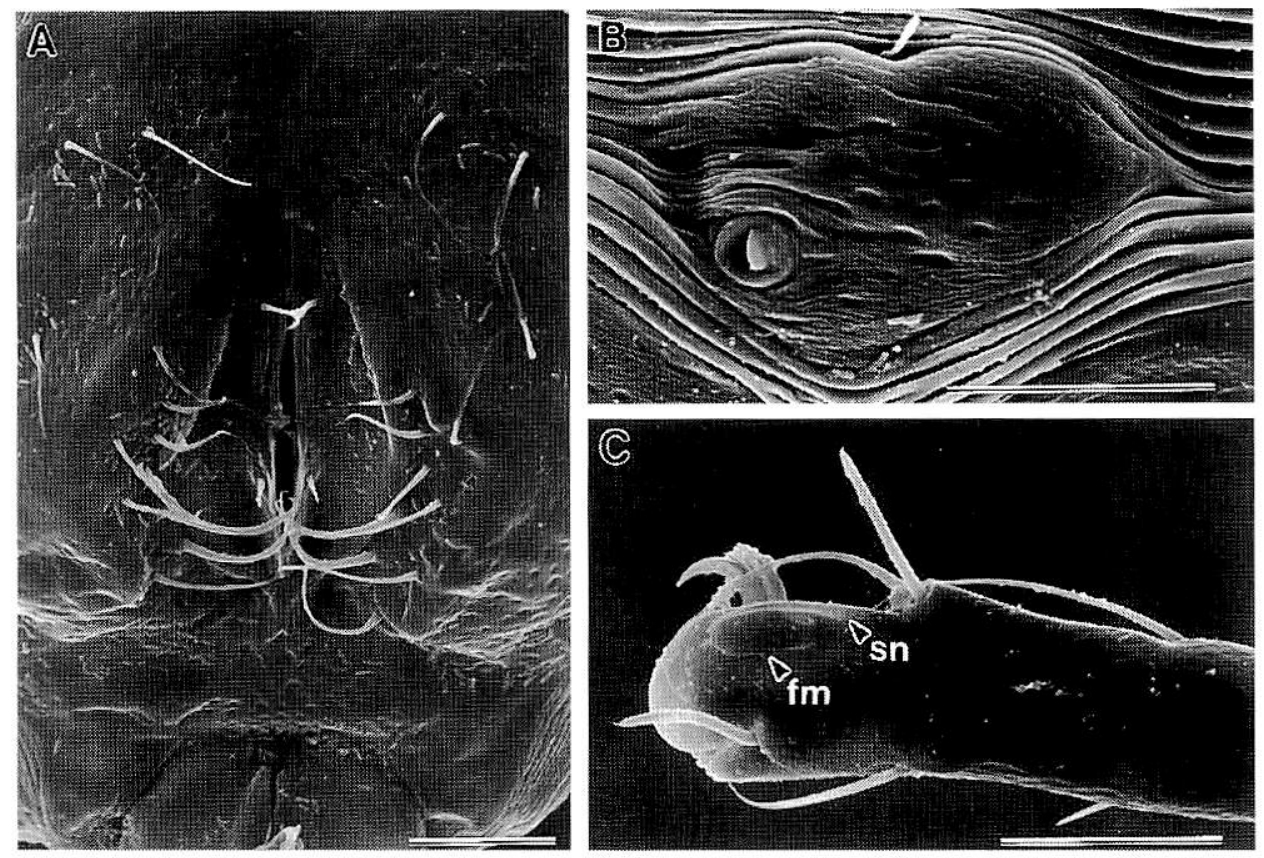

Fig. 3. Actacarus illustrans. Male: A, genital region; B, left ocular plate; C, distal region of left tarsus I. (sn, solenidion; fm, famulus) Scale bars $=10 \mu \mathrm{m}$.

1)-2-3-(4,5). Tarsus I (Fig. 3C) with 1 basidorsal seta, 1 filiform and 1 bacilliform basal fossary setae, 1 anteroventral seta, 2 distiventral setae, and 2 parambulacral setae. Solenidion (Fig. 3C) bacilliform, located on posterior surface of lamella. Famulus (Fig. 3C) blade-shaped, placed on the surface of lamella. Tarsus II with 1 basidorsal seta, 2 basal fossary setae, and 2 parambulacral setae. Solenidion long and terminally expanded. Tarsus III with 1 basidorsal seta, 3 fossary setae, and anterior filiform and posterior bacilliform parambulacral setae. Tarsus IV with 3 fossary setae and 2 filiform parambulacral setae.

Remarks. The length of the idiosoma shows regional variation: Vancouver specimens (우우, 188-195; $\sigma^{\nearrow} \sigma^{\nearrow}, 190-210$ ), Alaskan specimens (우우, 227-240; $\sigma^{7} \sigma^{7}$, 240-246), Japanese specimens (우우, 240-260; $\sigma^{\top} \sigma^{\top}, 250-285$ ). The body size increases gradually from the eastern to the western coasts of the North Pacific. Krantz (1976) presented a description of 3 nymphal stages on the basis of specimens from Schooner Creek, Oregon, USA. Deutonymphs, protonymphs, and larvae had idiosomal lengths of 280-312, 238-308, and 165-214, respectively. In the present study, however, the idiosomal length of deuto- and protonymphs from Vancouver Island are 188 and 170, respectively, quite different from those given by Krantz (1976).

Distribution (Fig. 1). North Pacific Ocean: Alaska, Oregon, Vancouver Island, Japan. 


\section{Actacarus octosetus sp. nov.}

(Figs 4-7)

Type series. Holotype: + , in coarse sand at $0.1 \mathrm{~m}$ depth, Date, Uchiura Bay, Pacific coast of Hokkaido, 25. vi.1990, H. Abé leg. Allotype: $\sigma^{7}$, data as for holotype. Paratypes:
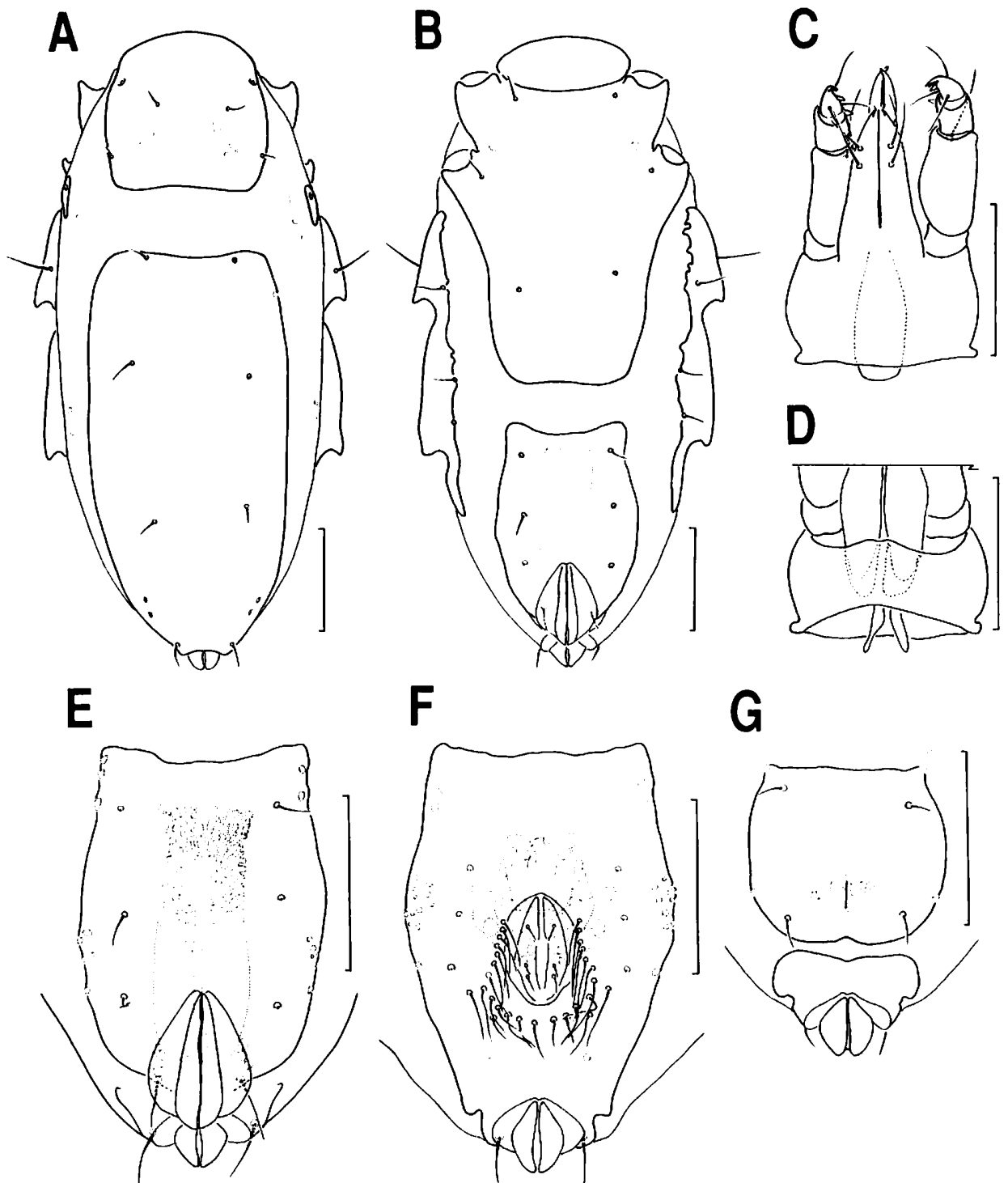

G
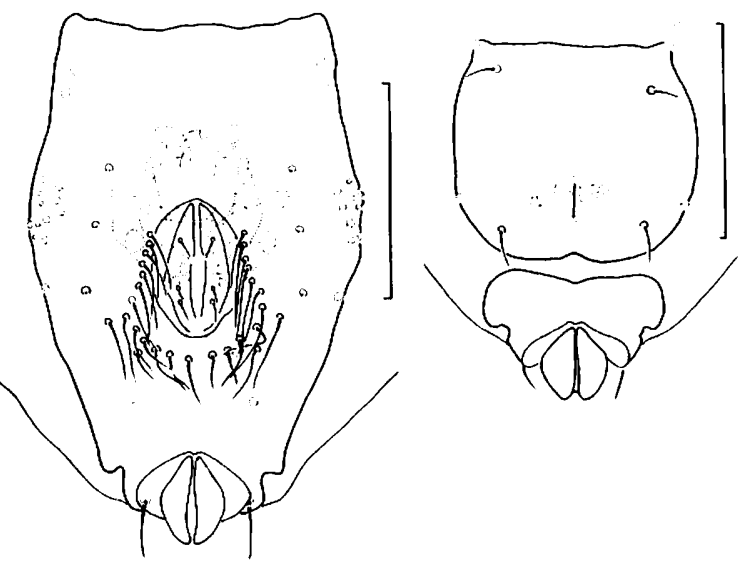

Fig. 4. Actacarus octosetus sp. nov. Female (holotype): A, idiosoma (dorsum); B, idiosoma (venter); C, gnathosoma (venter); D, proximal part of gnathosoma (dorsum); E, genitoanal region. Male (allotype): F, genitoanal region. Deutonymph (paratype): G, genitoanal region. Scalc bars $=50 \mu \mathrm{m}$. 
3 우우, $3 \sigma^{7} \sigma^{7}$, and 3 deutonymphs, data as for holotype.

Type-depositories. Holotype and allotype: National Science Museum, Tokyo. Paratypes: Division of Biological Sciences, Graduate School of Science, Hokkaido University, Sapporo; National Museum of Natural History (USNM) collection at the Systematic Entomology Laboratory, USDA, Beltsville, Maryland, USA.

Etymology. The specific epithet refers to 8 (octo) perigenital setae in the female.

Female (holotype): Idiosoma 310 long, 155 wide. Color in life semitransparent with brown specks medially.

Dorsum (Fig. 4A): Dorsal plates delicately punctate. Membranous cuticle ornamented with fine wavy striation. $A D$ and $P D$ separated by interval approximately 2.5 times as long as $\mathrm{AD}$. AD 80 long, 85 wide, with tiny areolation posteriorly. OC 20 long, with pore and tiny pit (Fig. 5B). PD 198 long, 108 wide. Dorsal pores distinct; $d p$ - $i$ on AD near anterolateral corners; $d p$-ii on $O C$; $d p$-iii and dp-iv on PD at posterolateral corners (Fig. 5A). Four pairs of oval subsurface pores in membranous cuticle dorsolaterally on idiosoma.

Chaetotaxy of dorsum: Dorsal setae short and filiform. Setae ds-i and ds-ii on AD; ds-iii-ds-vi (adanal setae) on PD.

Venter (Fig. 4B): AE 150 long, with pair of subsurface pores between coxae of legs I and II. PE 148 long, with series of tiny subsurface pores on ventral margin.

Chaetotaxy of epimeral region: epimeral setae filiform; aes- $\mathrm{i}$ on $\mathrm{AE}$ near ventral margin of coxa I; aes-ii-lat long and thick, on posterodorsal margin of $\mathrm{AE}$; aes-ii-v on $\mathrm{AE}$ near posteroventral margin; pes-iii-lat on dorsal margin of PE near insertion of leg III; pes-iii-v on ventral margin of PE near insertion of leg III; pes-iv-a on ventromedial margin of PE; pes-iv-p on posterior margin of PE near insertion of leg IV.

Genitoanal region (Figs 4E, 5A): GA 100 long, 75 wide. Genital foramen 40 long, 30 wide. Genital sclerites elongate. Anal foramen terminally placed, dorsad of genital foramen. Ovipositor (Fig. 4E) tubular, extending to the level of insertion of leg IV. Genital acetabula in 3 pairs.

Chaetotaxy of genitoanal region: Perigenital setae fine and filiform, 4 pairs arranged as in Figs $4 \mathrm{E}$ and $5 \mathrm{~A}$. Subgenital setae absent.

Gnathosoma (Figs 4C, 4D): 85 long, 65 wide; gnathosomal length/idiosomal length 0.27 ; base of gnathosoma with $\mathrm{L} / \mathrm{W} 0.62$, without setae. Anterior margin of tectum weakly convex (Fig. 4D). Rostrum (Figs 4C, 5C) 50 long, 28 wide, reaching to the distal end of $\mathrm{p}-2$, bearing 4 pairs of setae as follows: protorostrals tiny, placed ventrally near tip; deutorostrals very short, placed laterally; tritorostrals and basirostrals long, placed ventrally. Rostral sulcus reaching to level of $\mathrm{p}-1$. Chelicera (Fig. 5E) with movable digit bearing about 15 denticles on dorsal margin. Fixed digit reduced to a membrane. Cheliceral base 63 long. Palp 63 long, slightly bending down to venter; $\mathrm{p}-1$ short, cylindrical; $\mathrm{p}-2$ longest, nearly four times as long as $\mathrm{p}-1$, with 1 long filiform seta distidorsally; p-3 short, cylindrical, with 1 short spiniform seta anterodistally; p-4 (Fig. 5D) conical, of about same length as p-1, with 1 short spiniform seta anterodistally, 3 slender filiform setae proximally, 1 short fine seta distally, and bilobed terminal end.

Legs (Figs 6A-6D): Length of legs I, II, III IV $=225,180,208,208$, respectively. Tarsus I with small lateral claws compared with those on other legs. Combs developed on tarsi II, III, and IV. Median claws minute, bidentate on tarsus I and unidentate on other tarsi. Cavity present in claw. 

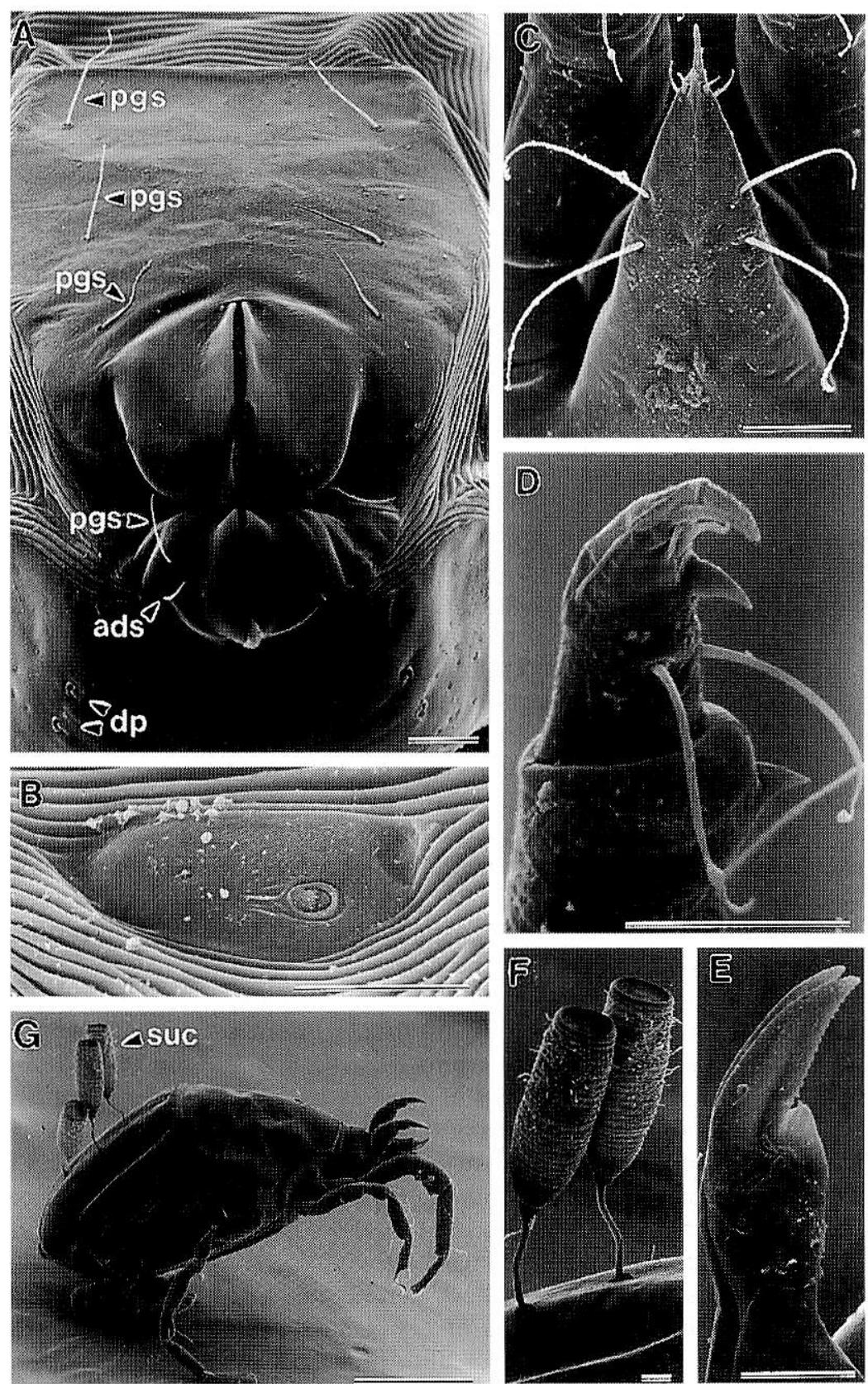

Fig. 5. Actacarus octosetus sp. nov. Female: A, genitoanal region; B, right ocular plate; C, rostrum (venter); D, distal region of palp; E, distal region of chelicera; F, suctorian loricas; $\mathrm{G}$, mite with attached suctorians. (pgs, perigenital seta; ads, adanal seta; dp, dorsal pore; suc, suctorians) Scale bars $=10 \mu \mathrm{m}$ (figs A-F), $100 \mu \mathrm{m}$ (fig. G). 


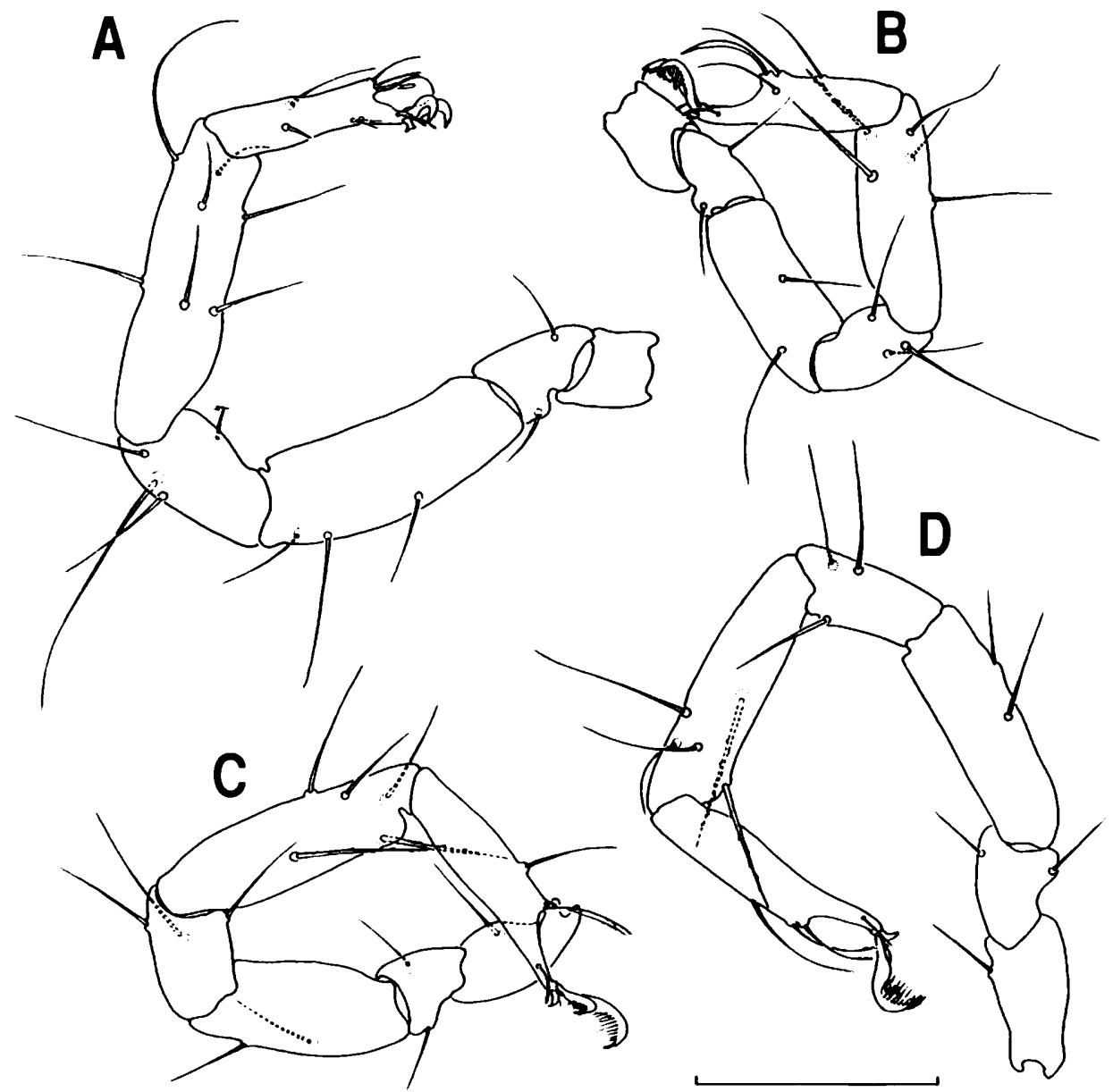

Fig. 6. Actacarus octosetus sp. nov. Female (holotype): A, left leg I; B, left leg II; C, right leg III; D, right leg IV. Scale bar $=50 \mu \mathrm{m}$.

Leg chaetotaxy as follows:

\begin{tabular}{lcccc}
\hline & Leg I & Leg II & Leg III & Leg IV \\
Trochanter & 0 & 0 & 1 & 1 \\
Basifemur & 2 & 2 & 2 & 2 \\
Telofemur & 3 & 2 & 2 & 2 \\
Genu & 4 & 3 & 3 & 3 \\
Tibia & 7 & 5 & 5 & 5 \\
\hline
\end{tabular}

Tarsus I (Fig. 7A) with 1 long filiform basidorsal seta, 2 filiform fossary setae, 1 fine spiniform anteroventral seta, and 2 short filiform distiventral setae. Fossary lamella well developed on posterior side of claw fossa. Solenidion (Fig. 7A) bacilliform, located on posterior surface of lamella. Famulus (Fig. 7A) blade-shaped, 

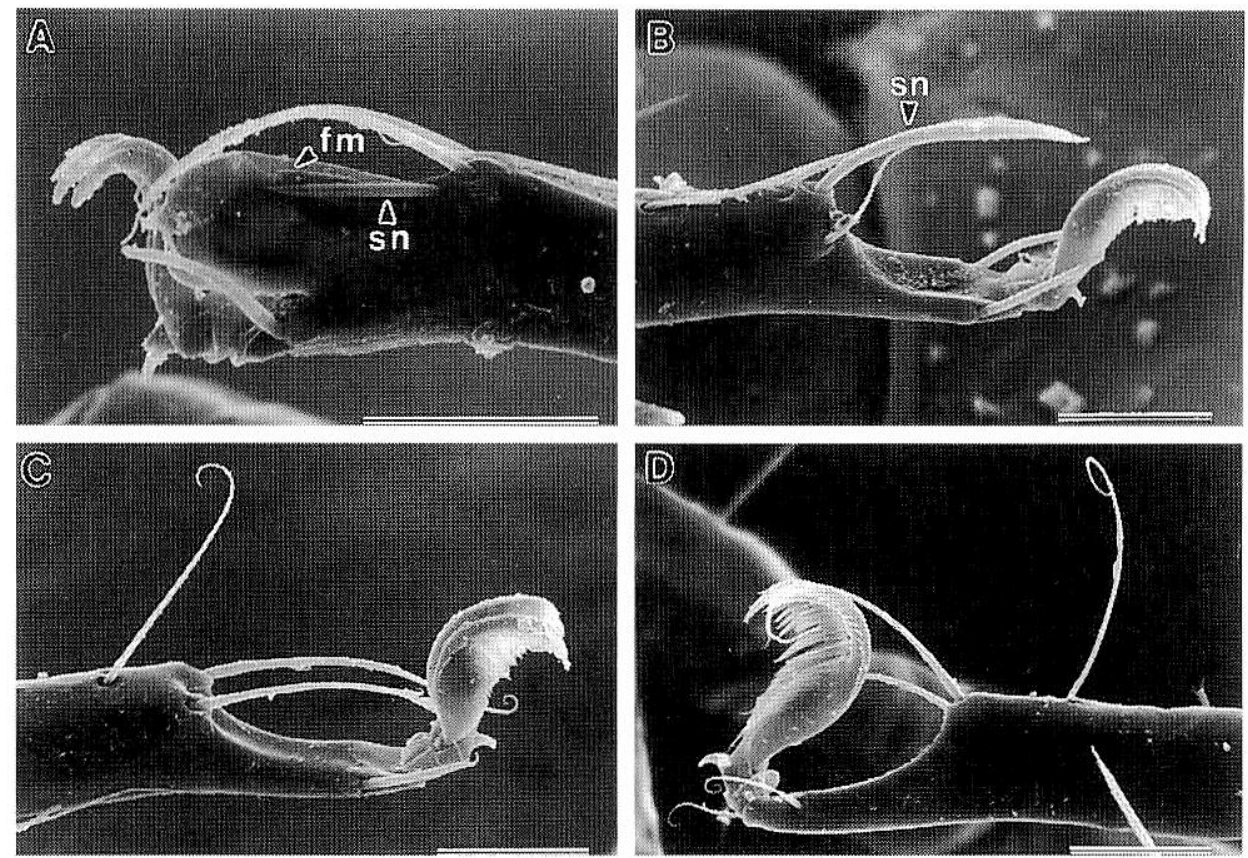

Fig. 7. Actacarus octosetus sp. nov. Female, distal region of tarsus: A, left tarsus I; B, left tarsus II ; C, right tarsus III; D, right tarsus IV. (sn, solenidion; fm, famulus) Scale bars $=10 \mu \mathrm{m}$.

placed on surface of lamella. Anterior and posterior parambulacral setae represented by single euphathidia. Lateral claws small compared with those on other legs. Tarsus II (Fig. 7B) with 1 filiform basidorsal seta and 2 fine filiform fossary setae. Solenidion (Fig. 7B) long and claviform, located on claw fossa. Anterior and posterior parambulacral setae represented by single euphathidia. Tarsus III (Fig. 7C) with 1 filiform dorsal seta, 2 weakly serrated fossary setae, and anterior filiform and posterior bacilliform parambulacral setae. Tarsus IV (Fig. 7 D) with 1 filiform dorsal seta, 2 weakly serrated fossary setae, and 2 fine filiform parambulacral setae.

Male (allotype): Idiosoma 315 long, 185 wide; gnathosoma 80 long, 60 wide; structures except for those of genitoanal region as in female. Genitoanal region (Fig. 4F): GA 110 long, 78 wide, slightly concave anteriorly. Genital foramen 30 long, 23 wide. Perigenital setae fine and filiform; 34 setae arranged as in Fig. 4F. Subgenital setae short and spiniform, arranged 1-2 on genital sclerites as shown in Fig. 4F. Adanal setae filiform, located on posterolateral corners of PD. Genital acetabula in 3 pairs. Spermatophorotype typical for genus.

Deutonymph (paratype): Idiosoma 280 long, 135 wide; gnathosoma 73 long, 55 wide. AD 75 long, 78 wide. PD 140 long, 88 wide. OC 15 long. Setae ds-i and ds-ii on AD; ds-iii-ds-vi (adanal setae) on PD. AE 125 long, with 3 pairs of epimeral setae. PE 118 long, with 1 dorsal and 3 ventral setae. Genitoanal region (Fig. 4G): Genital plate 55 long, 55 wide, rectangular in outline. Primordial genital slit 8 long, 2 wide. Perigenital setae filiform, 2 pairs arranged as in Fig. 4G. Subgenital setae absent. Anal plate 18 long, 40 wide. Genital acetabula in 2 pairs. Leg chaetotaxy from 
trochanter to tibia as follows: Leg I, 0-2-3-4-7; Leg II, 0-2-2-3-5; Leg III, 1-2-2-3-5; Leg IV, 1-1-2-3-5. Chaetotaxy of tarsi as in adult.

Morphological variation. Size ranges of idiosoma and gnathosoma as follows:

\begin{tabular}{lcc}
\hline & Adult $(\mathrm{n}=8)$ & Deutonymph $(\mathrm{n}=3)$ \\
Idiosoma-length & $295-330$ & $250-280$ \\
Idiosoma-width & $145-185$ & $125-135$ \\
Gnathosoma-length & $70-88$ & $58-73$ \\
Gnathosoma-width & $58-65$ & $53-55$ \\
\hline
\end{tabular}

Number of perigenital setae varying from 34 to 40 in males. Abnormally, female sometimes with 7 or 9 perigenital setae. Basifemora I-IV with $2-2-(1,2)-(0,1)$ setae in deutonymph.

Distribution (Fig. 1). Uchiura Bay, Hokkaido, northern Japan.

Remarks. The diagnostic character states of $A$. octosetus are 1) ds-ii on AD, 2) AE with 3 pairs of setae, 3) PE with 1 dorsal and 3 ventral setae, 4) GA with 4 pairs of perigenital setae in female, $34-40$ setae in male, 5) tarsus III with 3 dorsal setae, 6) ovipositor extending to level of insertion of leg IV. Actacarus octosetus resembles $A$. obductus described by Bartsch $(1977 \mathrm{a}, 1991 \mathrm{~b})$ from the north Atlantic Ocean in having 4 pairs of perigenital setae in the female and paired dorsal pores (ds-iii and ds-iv) on the posterior part of PD. The new species, however, is easily distinguished from $A$. obductus in having 3 epimeral setae on the ventral margin of $\mathrm{PE}$ and a greater number (34-40) of perigenital setae in the male.

Marine suctorians (Fig. 5F) were found on several specimens of Actacarus octosetus. Schulz $(1933,1938)$ described 2 suctorian species, Thecacineta halacari and Acineta benesaepta, attached to marine halacarids from the Norwegian coast. Grimaldi (1965) also reported Thecacineta associated with Actacarus pygmaeus from Sardinia. Morphologically, the present suctorians show a general resemblance to the above-mentioned species of Thecacineta. Several kinds of halacarids, viz. Actacarus, Copidognathus, and Thalassarachna, are sympatrically distributed in the sandy sediment of the collecting site. The suctorians are host-specific, being found exclusively on Actacarus octosetus. Seventeen of 36 mite individuals were associated with suctorians (Fig. 5G). The number of suctorians on each host individual varied from 1 to 3 . The posterior dorsal plate seems to be the preferred site for suctorians, since the suctorians were only found there (Fig. 5G). No distinct morphological differences were detected between the mites with and without suctorians. Consequently, it is possible that these suctorians have a phoretic association with marine halacarids.

\section{Acknowledgments}

I am very grateful to Dr. R. I.. Smiley (USDA, Beltsville) for the loan of the type specimens of Actacarus ortholectus. Heartfelt thanks are also due to Mr. K. Kinoshita (Hokkaido Tokai University. Sapporo) for providing me with specimens of $A$. illustrans from Vancouver Island, and to Dr. M. J. Weedon (Visiting Scientist, Hokkaido University, Sapporo) for correcting my English. This work was supported in part by a Research Grant from the Fujiwara Natural Ilistory Foundation. 


\section{References}

Abé, H. 1990. Two species of the genus Actacarus (Acari, Halacaridae) from Japan. Zoological Science 7: 111-126.

André, M. 1946. Halacariens marins. Faune de France 46: 1-152.

Bartsch, I. 1977a. Eine neue Actacarus-Art (Acari, Halacaridae) aus dem Bathyal vor der Küste von North Carolina, USA. Zoologica Scripta 6: 323-326.

Bartsch, I. 1977b. Interstitielle Fauna von Galapagos XX. Halacaridae (Acari). Mikrofauna des Meeresbodens 65: 1-108.

Bartsch, I. 1979. Halacaridae (Acari) from Oahu Island (Hawaiian Archipelago). Entomologische Mitteilungen aus dem Zoologischen Museum, Hamburg 6: 231-241.

Bartsch, I. 1983. Vorschlag zur Neugliederung des Systems der Halacaridae (Acari). Zoologische Jahrbücher, Systematik 110: 179-200.

Bartsch, I. 1988. Arenicolous Halacaridae (Acari) in Hawaiian waters. Proceedings, Hawaiian Entomological Society 28: 213-228.

Bartsch, I. 1991a. Arenicolous Halacaridae (Acari) from Hong Kong. Asian Marine Biology 8: 57-75.

Bartsch, 1. 1991 b. Taxonomic notes on halacarids (Acari) from the Skagerrak area. Helgoländer Meeresuntersuchungen 45: 97-106.

Bartsch, I. 1993. Arenicolous Halacaridae (Acari) from South-Western Australia. Pp. 73-103. In: Wells, F.E., Walker, D.I., Kirkman, H. and Lethbridge, R. (Eds) Proceedings of the Fifth International Marine Biological Workshop: The Marine Flora and Fauna of Rottnest Island, Western Australia. Western Australian Museum, Perth, 330 pp.

Bartsch, I. 1996. New records of Aclacarus from the Caribbean area, and notes on the subfamily Actacarinae and its species (Arachnida: Acari: Halacaridae). Senckenbergiana biologica 75 : 229-241.

Bartsch, I. and Schmidt, P. 1978. Interstitielle Fauna von Galapagos. XXII. Zur Ökologie der Halacaridae (Acari). Mikrofauna des Meeresbodens 69: 1- 37.

Grimaldi, P. 1965. Osservazioni su alcuni elementi del mesopsammon della Sardegna. Monitore zoologico italiano 73: 61-65.

Krantz, G. W. 1976. Arenicolous Halacaridae from the intertidal zone of Schooner Creek, Oregon (Acari: Prostigmata). Acarologia 18: 241-258.

Newell, I. M. 1951. Further studies on Alaskan Halacaridae (Acari). American Museum Novitates 1536: 1-56.

Newell, I. M. 1984. Antarctic Halacaroidea. Antarctic Research Series 40: 1-284.

Schulz, E. 1933. Beiträge zur Kenntnis mariner Suctorien. Zoologischer Anzeiger 103: 327-329.

Schulz, E. 1936. Actacarus pygmaeus n. g. n. sp., eine merkwürdige Meeresmilbe aus der Otoplanen-Zone der Nordsee. Kieler Meeresforschungen 1: 327-331.

Schulz, E. 1938. Beiträge zur Kenntnis mariner Suctorien. VII. Kieler Meeresforschungen 2: 354-355. 